\title{
Measuring illness insight in patients with alcohol-related cognitive dysfunction using the Q8 questionnaire: a validation study
}

This article was published in the following Dove Press journal:

Neuropsychiatric Disease and Treatment

I July 2016

Number of times this article has been viewed

\author{
Serge JW Walvoort ${ }^{1-3}$ \\ Paul T van der Heijden ${ }^{3,4}$ \\ Roy PC Kessels 1,2,5 \\ Jos IM Egger ${ }^{1-3,6}$ \\ 'Centre of Excellence for Korsakoff \\ and Alcohol-Related Cognitive \\ Disorders, Vincent van Gogh Institute \\ for Psychiatry, Venray, ${ }^{2}$ Donders \\ Institute for Brain, Cognition and \\ Behaviour, ${ }^{3}$ Behavioural Science \\ Institute, Radboud University, \\ Nijmegen, ${ }^{4}$ Reinier van Arkel Mental \\ Health Institute, 's-Hertogenbosch, \\ ${ }^{5}$ Department of Medical Psychology, \\ Radboud University Medical Center, \\ Nijmegen, ${ }^{6}$ Centre of Excellence for \\ Neuropsychiatry, Vincent van Gogh \\ Institute for Psychiatry, Venray, the \\ Netherlands
}

Aim: Impaired illness insight may hamper treatment outcome in patients with alcohol-related cognitive deficits. In this study, a short questionnaire for the assessment of illness insight (eg, the Q8) was investigated in patients with Korsakoff's syndrome (KS) and in alcohol use disorder (AUD) patients with mild neurocognitive deficits.

Methods: First, reliability coefficients were computed and internal structure was investigated. Then, comparisons were made between patients with KS and patients with AUD. Furthermore, correlations with the Dysexecutive Questionnaire (DEX) were investigated. Finally, Q8 total scores were correlated with neuropsychological tests for processing speed, memory, and executive function.

Results: Internal consistency of the Q8 was acceptable (ie, Cronbach's $\alpha=0.73$ ). The Q8 items represent one factor, and scores differ significantly between AUD and KS patients. The Q8 total score, related to the DEX discrepancy score and scores on neuropsychological tests as was hypothesized, indicates that a higher degree of illness insight is associated with a higher level of cognitive functioning.

Conclusion: The Q8 is a short, valid, and easy-to-administer questionnaire to reliably assess illness insight in patients with moderate-to-severe alcohol-related cognitive dysfunction.

Keywords: illness insight, anosognosia, alcohol use disorder, Korsakoff's syndrome, cognition, neuropsychological assessment

\section{Introduction}

Impairments in memory and executive function (EF) are core symptoms of Korsakoff's syndrome (KS), but are also present in patients with alcohol use disorder (AUD). ${ }^{1-6}$ Both memory and EF are key features for a successful behavioral change to remain abstinent and to restore societal functioning. ${ }^{7-10}$ One consequence of these cognitive dysfunctions in patients with AUD is impaired illness insight. ${ }^{11,12}$ That is, patients typically underestimate the amount of alcohol they have used and the duration of their alcohol addiction, and they also misjudge the severe and adverse consequences of alcohol addiction on daily life and health functioning. ${ }^{13-15}$ Impaired illness insight can be regarded as a continuum ranging from total denial of the disease to more subtle metacognitive awareness deficits. ${ }^{11}$ Illness insight comprises of awareness of illness, the capacity to view symptoms of the disease as pathological, and treatment adherence. $^{16}$

In patients with $\mathrm{KS}$, overestimation of their memory abilities or a failure to recognize their severity is common due to impaired metamemory. ${ }^{14,17}$ Compared to the information given by the patients themselves, information given by relatives, therapists,
Correspondence: Serge JW Walvoor Centre of Excellence for Korsakoff and Alcohol-Related Cognitive Disorders, Vincent van Gogh Institute for Psychiatry, Stationsweg 46, 5803 AC Venray, the Netherlands

Tel +3I 478527339

Fax +31 478527626

Email swalvoort@vvgi.nl (c) (1) (5) 2016 Walvoort et al. This work is published and licensed by Dove Medical Press Limited. The full terms of this license are available at https://www.dovepress.com/terms.php cc. hereby accept the Terms. Non-commercial uses of the work are permitted without any further permission from Dove Medical Press Limited, provided the work is properly attributed. For permission for commercial use of this work, please see paragraphs 4.2 and 5 of our Terms (https://www.dovepress.com/terms.php). 
and other professional caregivers report that these patients show a poor insight into and less awareness of their cognitive deficits. ${ }^{18}$ Impaired illness insight in alcohol-dependent patients might be related to severe retrograde amnesia, including deficits in autobiographical memory. ${ }^{19}$

A wide network of brain structures has been identified as being crucial for self-awareness, and includes the prefrontal and posterior parietal cortex, the rostral part of the anterior cingulate cortex, the insula, and the precuneus. ${ }^{12,20-22}$ Typically, these brain areas are susceptible to the negative effects of alcohol use. ${ }^{12,23-25}$ Although this would indicate that functional and structural changes in brain functioning underlie impaired illness insight, clinically, lack of illness insight is often misinterpreted as a motivational problem or alcoholic denial. ${ }^{26-29}$ Moreover, these alcohol-related cognitive deficits can affect the results of self-report questionnaires in such a way that it can lead to clinical misinterpretation. ${ }^{13,30-32}$ In order to avoid this misinterpretation of alcohol-related cognitive deficits, the combined use of self-reported information and information reported by informants who know the patient very well is essential for adequate diagnosis and in particular for the assessment of impaired self-awareness.

Bourgeois et $\mathrm{al}^{33}$ and Bourgeois et $\mathrm{al}^{34}$ developed and validated a short questionnaire for measuring illness insight in patients with severe psychopathology, the Q8 questionnaire, available in the French language. The Q8 is a short and easy-to-administer questionnaire for measuring illness insight by means of answering eight questions by the patient (Table S1 provides an English translation of the original French questions). After the patient has completed the Q8, a clinician who knows the patient very well rates each response with respect to its adequacy. The total score is the sum of the item scores (maximum $=8$ ). A score of $\leq 2$ indicates no illness insight; a score of 3-5 indicates poor illness insight; and a score of $\geq 6$ indicates good illness insight. Bourgeois et $\mathrm{al}^{34}$ examined the Q8 in a mixed-etiology psychiatric sample with severe psychopathology (eg, patients with schizophrenia, bipolar depression, and addiction). The authors concluded that the Q8 has adequate psychometric properties and concurrent validity. However, despite the fact that the Q8 was specifically designed for measuring levels of illness insight, until now no research has yet been published about its use in patients with alcohol-related cognitive deficits.

Therefore, in the present study, we aimed to investigate the psychometric properties of the Dutch version of the Q8 in patients with severe and mild alcohol-related cognitive deficits. First, the internal consistency was investigated. Second, the internal structure was studied. We expected all eight items to represent one factor. Third, the difference in Q8 total scores between KS patients and AUD patients with moderate cognitive deficits was considered. We expected that KS patients would have a lower Q8 total score than other AUD patients. Next, the Q8 scores were correlated with the Dysexecutive Questionnaire (DEX) discrepancy score, a widely used measure to assess executive problems in daily life as reported by the patient and an informant. ${ }^{35} \mathrm{We}$ expected that a lower DEX discrepancy score correlated with a lower Q8 total score, indicating impaired illness insight. Finally, correlations of the Q8 with neuropsychological tests for executive functioning, memory, and processing speed were calculated. We hypothesized that impaired illness insight (ie, a lower Q8 total score) correlates higher with severe cognitive dysfunction in $\mathrm{KS}$ patients than in AUD patients with mild cognitive deficits.

\section{Methods}

\section{Participants}

All data were collected as part of routine outcome monitoring of clinical testing and all participants signed a treatment plan. The Vincent van Gogh Institutional Review Board did not require patient consent be obtained, as the confidentiality of participants' identities was maintained throughout the study process. Both the study and study procedure were approved by the Vincent van Gogh Institutional Review Board. The study was carried out in accordance with the Declaration of Helsinki and the Guidelines for Good Clinical Practice established by the International Conference on Harmonization $(\mathrm{CPMP} / \mathrm{ICH}=135 / 95)$. Ninety-seven patients completed the Q8 as part of routine clinical assessment (Table 1). All were inpatients of the Centre of Excellence for Korsakoff and alcohol-related cognitive disorders of the Vincent van Gogh Institute for Psychiatry in Venray, the Netherlands. Forty-two patients were diagnosed as KS patients fulfilling the Diagnostic and Statistical Manual of Mental Disorders, 5 th edition criteria for alcohol-induced major neurocognitive disorder $^{36}$ (including the presence of a persistent memory impairment resulting in severe deficits in social functioning, the absence of delirium or dementia, a history of alcohol abuse disorder, evidence for a history of Wernicke encephalopathy, confabulation behavior, and history of malnutrition or thiamine deficit) as established by neurological, psychiatric, neuroradiological, and neuropsychological examinations.

The AUD group consisted of 55 patients with a history of chronic alcohol abuse with mild neurocognitive impairments. All AUD control patients met the Diagnostic and Statistical Manual of Mental Disorders, 5th edition criteria for mild neurocognitive disorder. ${ }^{36}$ The cognitive 
Table I Descriptives of the total group $(\mathrm{N}=97)$ and differences between $\mathrm{KS}(\mathrm{N}=42)$ and AUD patients $(\mathrm{N}=55)$

\begin{tabular}{|c|c|c|c|c|c|c|c|c|c|c|}
\hline & \multicolumn{2}{|c|}{ Total $(n=97)$} & \multicolumn{2}{|c|}{ KS $(n=42)$} & \multicolumn{2}{|c|}{ AUD $(n=55)$} & \multirow[t]{2}{*}{$t^{a}$} & \multirow{2}{*}{$\frac{U}{1,137}$} & \multirow{2}{*}{$\begin{array}{l}P \text {-value } \\
0.89\end{array}$} & \multirow[t]{2}{*}{ Cohen's d } \\
\hline Education (mode and range) & $4(2-7)$ & & $4(2-6)$ & & $4(2-7)$ & & & & & \\
\hline Alcohol use in years (range) & $2-55$ & & $2-48$ & & $2-55$ & & & & & \\
\hline \multirow[t]{2}{*}{ Abstinence in days (range) } & $42-693$ & & $42-693$ & & $42-186$ & & 1.14 & & 0.26 & \\
\hline & Mean & SD & Mean & SD & Mean & SD & & & & \\
\hline Age (years) & 55.84 & 8.66 & 57.36 & 8.77 & 54.67 & 8.47 & 1.52 & & 0.13 & \\
\hline \multicolumn{11}{|l|}{ Cognitive measures } \\
\hline NART & 92.43 & 15.10 & 89.67 & 14.64 & 94.55 & 15.55 & -1.59 & & 0.12 & \\
\hline PSI* & 81.37 & 15.09 & 75.2 & 13.85 & 86.06 & 14.39 & -3.70 & & 0.00 & -0.77 \\
\hline CVLT delayed free recall & 5.79 & 4.72 & 2.4 & 3.76 & 8.38 & 3.61 & -7.94 & & 0.00 & -1.62 \\
\hline MSET & 2.42 & 1.27 & 1.76 & 1.10 & 2.93 & 1.15 & -5.03 & & 0.00 & -1.04 \\
\hline \multicolumn{11}{|l|}{ Questionnaires } \\
\hline DEX-S & 21.63 & 11.08 & 19.60 & 11.13 & 23.18 & 10.88 & -1.59 & & 0.11 & -0.33 \\
\hline DEX-I & 23.21 & 12.95 & 28.40 & $|2.0|$ & 19.24 & $|2.3|$ & 3.67 & & 0.00 & 0.75 \\
\hline DEX-D & -1.58 & 16.39 & -8.81 & 15.97 & 3.95 & 14.57 & 3.67 & & 0.00 & -0.83 \\
\hline Q8 & 3.34 & 2.15 & 2.48 & 2.17 & 4.00 & 1.90 & -3.69 & & 0.00 & -0.75 \\
\hline
\end{tabular}

Notes: Values in bold indicate $P<0.05$. Education level was assessed using seven categories in accordance with the Dutch educational system ( $I=$ less than primary school; 7= university degree). NART, National Adult Reading Test (standard score); 5 *PSI (standard score) of the WAIS-III. CVLT, California Verbal Learning Test (raw score); MSET, modified six elements test (standard score); DEX-S, DEX-self (raw score); DEX-I, DEX-informant (raw score); DEX-D, discrepancy score of DEX-self (raw score) minus DEX-informant (raw score). alndependent samples $t$-tests. Q8 total score maximum $=8$.

Abbreviations: AUD, alcohol use disorder; KS, Korsakoff syndrome; PSI, Processing Speed Index; SD, standard deviation; WAIS-III: Wechsler Adult Intelligence Scale Third Edition.

impairments were substantiated through neuropsychological assessment. None of the AUD patients met the proposed clinical criteria for KS or alcohol-related dementia. ${ }^{37}$ The neurocognitive impairments were not a result of another medical condition or use of other substances. In both groups, the cognitive deficits were substantiated by neuropsychological assessment.

All patients were abstinent from alcohol for at least 42 days at the time of testing. Education level was assessed using seven categories in accordance with the Dutch educational system $\left(1=\right.$ less than primary school; $7=$ university degree $\left.{ }^{38}\right)$. No significant differences were found between the groups regarding sex distribution $\left(\chi^{2}[1]=0.000, P=0.996\right)$. Descriptives of the total group $(\mathrm{N}=97)$ and differences between the KS $(\mathrm{N}=42)$ and AUD patients $(\mathrm{N}=55)$ are listed in Table 1.

\section{Measures \\ Questionnaires}

The Q8 has been developed and validated in French. For this study, the Q8 was translated into Dutch and slightly adapted using the original French questions by a clinical neuropsychologist with expertise in alcohol-related cognitive disorders (Dr Arie Wester, see "Acknowledgments" section). ${ }^{33,34}$ Consensus was reached in the translation by all authors. The resulting research version of the Q8 consists of eight questions (Table S1), for example: "Do you experience limitations in your professional life, your family life, or in your social life?" and was administered 5 weeks after admission to the clinic. An internal consistency of 0.81 was found in a previous study. ${ }^{33,34}$

The DEX, a subtest of the Behavioural Assessment of the Dysexecutive Syndrome ${ }^{35}$ was administered. There are two versions: a patient rating scale (DEX-S) and a rating scale for informants (DEX-I; eg, relatives, friends, or professional caregivers) who know the patient very well in relation to the daily activities/functioning. Both versions are 20 -item scales in which each item is rated $0=$ never, $1=$ occasionally, $2=$ sometimes, $3=$ fairly often, or $4=$ very often. The DEX incorporates cognitive, affective, and behavioral aspects of the dysexecutive syndrome. An example of such a question is "I find it difficult to keep my mind on something, and am easily distracted." Both the patient and his/her primary professional caregiver from our department completed the DEX. In order to investigate the dissociation between self-report and behavior, which is commonly seen in addiction, ${ }^{12}$ discrepancy scores for the DEX (DEX-D) were calculated by subtracting the informant scores from the self-ratings. ${ }^{11,35}$ A negative discrepancy score indicates higher ratings by the patient than by the caregiver, suggestive of illness insight, whereas a positive discrepancy score points at a lower rating by the caregiver than by the patient and a lack of illness insight. Validity of DEX-D scores for detecting poor insight has been established previously. David et al, ${ }^{11}$ for instance, found that DEX-D was highly discrepant in patients with Alzheimer and patients with brain injury and should be regarded as a measure of awareness of dysexecutive problems. 


\section{Neuropsychological measures}

The Modified Six Elements Test (MSET) of the Behavioural Assessment of the Dysexecutive Syndrome ${ }^{35,39}$ was used as a cognitive measure of daily EF and discriminates at a clinically significant level between KS and non-KS patients. ${ }^{1,40}$

The delayed free recall raw score of the Dutch version of the California Verbal Learning Test $\left(\mathrm{CVLT}^{41}\right)$ was used in the analysis. The CVLT is a word-list learning test that has proven to be sensitive in detecting memory impairment in chronic alcoholic patients (Walvoort et al, unpublished data, 2016). ${ }^{42}$

Finally, the Processing Speed Index (PSI) of the Wechsler Adult Intelligence Scale - Third Edition (WAIS-III ${ }^{43}$ ) was used, which consists of the subtests Digit Symbol Coding and Symbol Search. The PSI has proven to be sensitive in detecting impairment in processing speed (Walvoort et al, unpublished data, 2016).

\section{Procedure and analysis}

Informed consent was obtained from all participants. The assessment of the DEX questionnaires and the neuropsychological tests were administered after patients had been abstinent from alcohol or other nonmedical drugs for at least 6 weeks. ${ }^{44}$ The neuropsychological tests were assessed by an experienced psychologist. In this study, the Q8 questionnaire was evaluated by an experienced clinical neuropsychologist who knows the patient well, 2 weeks prior to neuropsychological assessment. Reliability of the Q8 was measured by computing Cronbach's $\alpha$ and split-half reliability. Internal structure of the Q8 was investigated by principal component analysis with varimax rotation. Parallel analysis was performed to determine the number of components that should be extracted. ${ }^{45,46}$

Independent $t$-tests were performed to measure differences between KS patients and AUD patients (Table 1). Pearson's correlations coefficients were computed between the Q8, the DEX-S, DEX-I, DEX-D score, and the neuropsychological measures (MSET, CVLT, and PSI) for both groups pooled together.

\section{Results}

Cronbach's $\alpha$ for the Q8 questionnaire was found to be 0.73 , and Spearman-Brown coefficient was 0.70 , which are acceptable. ${ }^{47}$ Principal component analysis on the items in the total sample revealed one component accounting for $35 \%$ of the variance. Principal component analysis was repeated in both subsamples to investigate whether the factor structure was robust in both subsamples. In both subsamples, one factor appeared with somewhat higher loadings in the KS subsample ( $\mathrm{M}=0.63)$ than in the AUD subsample $(\mathrm{M}=0.47)$. The coefficient of congruence, used to compare the factors in both subsamples, was 0.89 . As a rule of thumb, Harman ${ }^{48}$ proposed that factors are congruent if the coefficient of congruence is equal to or greater than 0.94 .

As Table 1 indicates, the KS group demonstrated significantly lower scores on the Q8 questionnaire than the AUD controls. On the Q8, $64 \%$ of the KS patients scored $<2$ versus $23 \%$ of the AUD controls. Table 2 demonstrates significant correlations between the Q8 and the DEX, CVLT recall, MSE, and PSI. Correlations of 0.10 are considered small, and correlations of 0.30 can be considered medium. ${ }^{49}$ The positive correlations between Q8 and the DEX-S indicate that a higher level of illness insight is associated with a higher level of self-reported complaints on the DEX-S. Significant negative correlations between the Q8 and DEX-I were found, indicating that lower scores on the Q8 are associated with higher levels of observed dysexecutive problems by the informant. Moreover, the DEX-D score showed a positive correlation with the Q8, indicating that lower DEX-D scores (more symptoms observed by the professional caregiver than by the patient) are related with lower scores on the Q8. Positive correlations between the neuropsychological measures (MSET, CVLT, and PSI) and the Q8 were found, revealing that better cognitive performance is associated with a higher level of illness insight.

\section{Discussion}

This study is the first in using the Q8 questionnaire in patients with severe and moderate alcohol-related cognitive dysfunction for assessing illness insight. Internal consistency

Table 2 Pearson's correlations between the Q8, the DEX, the CVLT, the MSET, and PSI

\begin{tabular}{|c|c|c|c|c|c|c|}
\hline & \multicolumn{3}{|c|}{ DEX total score } & \multicolumn{3}{|c|}{ Neuropsychological measures } \\
\hline & Self & Informant & Discrepancy & CVLT delayed free recall & MSET & PSI \\
\hline Q8 & $0.26 *$ & $-0.30 * *$ & $0.4 I^{* *}$ & $0.28 * *$ & $0.35^{* *}$ & $0.26 *$ \\
\hline
\end{tabular}

Notes: $* P<0.05 ; * * P<0.01$. Discrepancy $=D E X$-self score minus DEX-informant score. Q8 total score maximum $=8$.

Abbreviations: DEX, Dysexecutive Questionnaire; CVLT, California Verbal Learning Test; MSET, modified six elements test; PSI, Processing Speed Index. 
split-half reliability and factor analysis proved that the Q8 has acceptable psychometric characteristics to assess (lack of) illness insight in patients with moderate-to-severe AUD. The Q8 scores of KS patients differ from that of AUD patients with less severe cognitive impairments, and the Q8 demonstrates medium correlations with the DEX-D, contributing to the concurrent validity of the $\mathrm{Q} 8$. These findings demonstrate the concurrent validity of the Q8 total score. Finally, as expected, better illness insight, as measured with the Q8, correlated with a better performance on measures of EF (the MSET), memory (CVLT delayed free recall), and processing speed (PSI).

Because the Q8 incorporates self-reported thoughts and beliefs of the patient as well as an evaluation by a caregiver who knows the patient very well, it has clinical potential as a valid tool for assessing illness insight in patients with severe psychopathology. Since it consists of eight items, it has a shorter administration time than the DEX-D. In addition, the Q8 measures illness insight in a more direct manner than the DEX-D. The DEX-D, being a measure of awareness in dysexecutive symptoms, is a more indirect way of measuring illness insight by comparing the "self" and "other" ratings. ${ }^{11}$ It should be noted that it is not always easy to gather information of relevant others, because the social network of AUD patients is often limited.

Another limitation of the Q8 is that data on test-retest reliability are not available from the studies of Bourgeois et $\mathrm{al}^{33,34}$ or from the present study. Future research should address this and could also examine the use of the Q8 in addicted patients without cognitive dysfunction, as the addiction itself also affects illness insight and selfawareness. ${ }^{18,20,50,51}$ Also, it would be interesting to evaluate the course of illness insight by assessing the Q8 on several occasions during abstinence. Kim et al, ${ }^{52}$ for instance, examined 117 male alcoholic patients who were abstinent for up to 1 year after treatment using a self-report questionnaire and found that insight might improve during the course of abstinence. Alternatively, one could argue that this improved insight may be due to improved cognitive function, in line with findings that cognitive function in alcoholic patients recovers to some extent during abstinence. ${ }^{44,53}$

\section{Conclusion}

The results of this study confirm that the Q8 questionnaire is a reliable and valid measure that provides a significant contribution to the assessment of illness insight in patients with moderate and severe alcohol-related cognitive dysfunction. It should be stressed that the assessment of illness insight should always be performed by using different sources of information (eg, neuropsychological measures, self-report questionnaires, and information from professional caregivers) to further optimize clinical decision making and treatment selection.

\section{Acknowledgment}

The authors thank Dr Arie Wester, clinical neuropsychologist and founder of the Korsakoff clinic in Venray, the Netherlands, for his stimulating role in this research as well as his contribution to the Q8 translation and data collection. In July 2015, sadly, Dr Wester passed away.

\section{Disclosure}

The authors report no conflicts of interest in this work.

\section{References}

1. Van Oort R, Kessels RPC. Executive dysfunction in Korsakoff's syndrome: time to revise the DSM criteria for alcohol-induced persisting amnestic disorder? Int J Psychiatry Clin Pract. 2009;13:78-81.

2. Goudriaan AE, Oosterlaan J, De Beurs B, van den Brink W. Neurocognitive functions in pathological gambling: a comparison with alcohol dependence, Tourette syndrome and normal controls. Addiction. 2006; 101:534-547.

3. Ihara H, Berrios GE, London M. Group and case study of the dysexecutive syndrome in alcoholism without amnesia. J Neurol Neurosurg Psychiatry. 2000;68:731-737.

4. Oscar-Berman M, Kirkley SM, Gansler DA, Couture A. Comparisons of Korsakoff and non-Korsakoff alcoholics on neuropsychological tests of prefrontal brain functioning. Alcohol Clin Exp Res. 2004;28: 667-675.

5. Loeber S, Duka T, Welzel H, et al. Impairment of cognitive abilities and decision making after chronic use of alcohol: the impact of multiple detoxifications. Alcohol Alcohol. 2009;44:372-381.

6. McCrady BS, Smith DE. Implications of cognitive impairment for the treatment of alcoholism. Alcohol Clin Exp Res. 1986;10:145-149.

7. Blume AW, Marlatt GA. The role of executive cognitive functions in changing substance use: what we know and what we need to know. Ann Behav Med. 2009;37:117-125.

8. Crews FT, Buckley T, Dodd PR, et al. Alcoholic neurobiology: changes in dependence and recovery. Alcohol Clin Exp Res. 2005;29: 1504-1513.

9. Le Berre AP, Vabret F, Cauvin C, et al. Cognitive barriers to readiness to change in alcohol-dependent patients. Alcohol Clin Exp Res. 2012;36: 1542-1549.

10. Tate R, Kennedy M, Ponsford J, et al. INCOG recommendations for management of cognition following traumatic brain injury, part III. J Head Trauma Rehabil. 2014;29:338-352.

11. David AS, Bedford N, Wiffen B, Gilleen J. Failures of metacognition and lack of insight in neuropsychiatric disorders. Philos Trans $R$ Soc Lond B Biol Sci. 2012;367:1379-1390.

12. Goldstein RZ, Craig AD, Bechara A, et al. The neurocircuitry of impaired insight in drug addiction. Trends Cogn Sci. 2009;13:372-380.

13. Lincoln R, Rosenthal CF, Malte CA, Simpson T. A pilot study of memory impairment associated with discrepancies between retrospective and daily recall of alcohol consumption. Am J Addict. 2011;20: 568-574.

14. Le Berre AP, Pinon K, Vabret F, et al. Study of metamemory in patients with chronic alcoholism using a feeling-of-knowing episodic task. Alcohol Clin Exp Res. 2010;34:1888-1898. 
15. Volkow N, Li TK. The neuroscience of addiction. Nat Neurosci. 2005;8: 1429-1430.

16. David AS. On insight and psychosis: discussion paper. $J$ R Soc Med. 1990;83:325-329.

17. Shimamura AP, Squire LR. Memory and metamemory: a study of the feeling-of-knowing phenomenon in amnestic patients. J Exp Psychol Learn Mem Cogn. 1986;12:452-460.

18. Verdejo-García A, Pérez-García M. Substance abusers' self-awareness of the neurobehavioral consequences of addiction. Psychiatry Res. 2008; 158:172-180.

19. Poncin M, Neumann A, Luminet O, Van de Weghe N, Philippot P, de Timary P. Disease recognition is related to specific autobiographical memory deficits in alcohol-dependence. Psychiatry Res. 2015;230(2): $157-164$.

20. Moeller SJ, Goldstein RZ. Impaired self-awareness in human addiction: deficient attribution of personal relevance. Trends Cogn Sci. 2014;18: 635-641.

21. Prigatano G, Johnson SC. The three vectors of consciousness and their disturbances after brain injury. Neuropsychol Rehabil. 2003;13:13-29.

22. Cavanna AE, Trimble MR. The precuneus: a review of its functional anatomy and behavioural correlates. Brain. 2006;129:564-583.

23. Bates ME, Barry D, Bowden SC. Neurocognitive impairment associated with alcohol use disorders: implication for treatment. Exp Clin Psychopharmacol. 2002;10:193-212.

24. Rosenbloom M, Pfefferbaum A. Magnetic resonance imaging of the living brain: evidence for brain degeneration among alcoholics and recovery with abstinence. Alcohol Res Health. 2008;31:362-376.

25. Sullivan EV, Pfefferbaum A. Neurocircuitry in alcoholism: a substrate of disruption and repair. Psychopharmacology. 2005;180:583-594.

26. Dean AC, Kohno M, Morales AM, Ghahremani DG, London ED. Denial in methamphethamine users: associations with cognition and functional connectivity in brain. Drug Alcohol Depend. 2015;151:84-91.

27. Moeller SJ, Konova AB, Parvaz A, et al. Functional, structural, and emotional correlates of impaired insight in cocaine addiction. JAMA Psychiatry. 2014;71:61-70.

28. Duffy JD. The neurology of alcoholic denial: implications for assessment and treatment. Can J Psychiatry. 1995;40(5):257-263.

29. Rinn W, Desai N, Rosenblatt H, Gastfriend DR. Addiction denial and cognitive dysfunction: a preliminary investigation. J Neuropsychiatry Clin Neurosci. 2002;14:52-57.

30. Egger JIM, Wester AJ, De Mey HRA, Derksen JJL. Korsakoff's syndrome on the MMPI-2. Acta Neuropsychiatr. 2002;14:231-236.

31. Johnson-Greene D, Adams KM, Gilman S, Junck L. Relationship between neuropsychological and emotional functioning in severe chronic alcoholism. Clin Neuropsychol. 2002;16:300-309.

32. Walvoort SJW, Wester AJ, Egger JIM. Neurocognitive parameters should be incorporated in the Minnesota Multiphasic Personality Inventory-2 assessment of patients with alcohol use disorders. Drug Alcohol Rev. 2012;31:550-557.

33. Bourgeois ML, Koleck M, Roig-Morrier R. Mesure de la conscience du trouble chez 100 malades hospitalisés en psychiatrie [Awareness of disorder (its measure in 100 psychiatric inpatients)]. Ann Med Psychol (Paris). 2002;160:444-450. French.

34. Bourgeois ML, Koleck M, Jais E. Validation de l'échelle d'insight Q8 et évaluation de la conscience de la maladie chez 121 patients hospitalisés en psychiatrie [Validation of the insight Q8 scale and evaluation of the awareness disorder in 121 psychiatric inpatients]. Ann Med Psychol. 2002;160:512-517. French.
35. Wilson BA, Alderman N, Burgess PW, Emslie H, Evans JJ. Manual for the Behavioural Assessment of the Dysexecutive Syndrome. Bury St Edmunds, UK: Thames Valley Test Company; 1996.

36. American Psychiatric Association. Diagnostic and Statistical Manual of Mental Disorders. 5th ed. Washington, DC: American Psychiatric Association; 2013.

37. Oslin D, Atkinson RM, Smith DM, Hendrie H. Alcohol related dementia: proposed clinical criteria. Int J Geriatr Psychiatry. 1998;13: 203-212.

38. Verhage, F. Intelligentie en leeftijd: Onderzoek bij Nederlanders van twaalf tot zevenenzeventig jaar [Intelligence and Age: Study of a Dutch Population in the Range of Twelve to Seventy-Seven Years]. Assen, the Netherlands: Van Gorcum; 1964. Dutch.

39. Fernández-Serrano MJ, Pérez-García M, Perales JC, Verdejo-García A. Prevalence of executive dysfunction in cocaine, heroin and alcohol users enrolled in therapeutic communities. Eur J Pharmacol. 2010; 626:104-112.

40. Maharasingam M, Macniven JAB, Mason, OJ. Executive functioning in chronic alcoholism and Korsakoff syndrome. J Clin Exp Neuropsychol. 2013;35(5):501-508.

41. Delis DC, Kramer JH, Kaplan E, Ober BA. The California Verbal Learning Test. San Antonio, TX: Psychological Corporation; 1987.

42. Wester AJ, Roelofs RL, Egger JIM, Kessels RPC. Assessment of alcohol-related memory deficits: a comparison between the Rivermead Behavioural Memory Test and the California Verbal Learning Test. Brain Impair. 2014;15:18-27.

43. Wechsler D. WAIS III-NL: Nederlandstalige bewerking: Technische handleiding [The Dutch WAIS III. Technical Manual]. Amsterdam, the Netherlands: Pearson Assessment; 2005. Dutch.

44. Walvoort SJW, Wester AJ, Egger JIM. Neuropsychologische diagnostiek en cognitieve functies bij alcoholabstinentie [The neuropsychology of cognitive functions in alcohol abstinence]. Tijdschr Psychiatr. 2013;55:101-111. Dutch.

45. Glorfeld LW. An improvement on Horn's parallel analysis methodology for selecting the correct number of factors to retain. Educ Psychol Meas. 1995;55:377-393.

46. Horn JL. A rationale and test for the number of factors in factor analysis. Psychometrika. 1965;30:179-185.

47. Nunnaly JC. Psychometric Theory. New York, NY: McGraw Hill; 1978.

48. Harman HH. Modern Factor Analysis. 3rd ed. Chicago, IL: University of Chicago Press; 1976.

49. Cohen J. A power promer. Psychol Bull. 1992;112:155-159.

50. Goldstein RZ, Volkow ND. Dysfunction of the prefrontal cortex in addiction: neuroimaging findings and clinical implications. Nat Rev Neurosci. 2011;12:652-669.

51. Volkow ND, Wang G, Fowler JS, Tomasi D. Addiction circuitry in the human brain. Annu Rev Pharmacol Toxicol. 2012;52:321-336.

52. Kim JS, Park BK, Kim GJ, et al. The role of alcoholic's insight in abstinence from alcohol in male Korean alcohol dependents. J Korean Med Sci. 2007;22:132-137.

53. Stavro K, Pelletier J, Potvin S. Widespread and sustained cognitive deficits in alcoholism: a meta-analysis. Addict Biol. 2013;18:203-213.

54. Schmand B, Lindeboom J, Van Harskamp F. De Nederlandse Leestest voor Volwassenen Handleiding [The Dutch National Adult Reading Test Manual]. Amsterdam, the Netherlands: Pearson Information and Assessment B.V.; 1992. Dutch. 


\section{Supplementary material}

Table SI English version of the Q8

\begin{tabular}{ll}
\hline Q8 questions & Score
\end{tabular}

I. Why are you here?

2. Do you feel that you are ill? YES/NO

3. Which disease or disorder do you have?

4. What is the cause of this?

5. Do you suffer psychologically or do you experience feelings of guilt? YES/NO

6. Do you experience limitations in your professional life, your family life, or in your social life? YES/NO

7. How can we help you?

8. Do you think you can be treated?

YES/NO

Q8 total score

Notes: Adapted and translated from Bourgeois ML, Koleck M, Jais E. Validation de l'échelle d'insight Q8 et évaluation de la conscience de la maladie chez I2I patients hospitalisés en psychiatrie [Validation of the insight Q8 scale and evaluation of the awareness disorder in I2I psychiatric inpatients]. Ann Med Psychol. $2002 ; 160: 5$ I2-5I7.

French. Copyright (? 2002 Éditions scientifiques et médicales Elsevier SAS. All rights reserved. Reproduced with permission.'

\section{Reference}

1. Bourgeois ML, Koleck M, Jais E. Validation de l'échelle d'insight Q8 et évaluation de la conscience de la maladie chez 121 patients hospitalisés en psychiatrie [Validation of the insight Q8 scale and evaluation of the awareness disorder in 121 psychiatric inpatients]. Ann Med Psychol. 2002;160:512-517. French.

Neuropsychiatric Disease and Treatment

\section{Publish your work in this journal}

Neuropsychiatric Disease and Treatment is an international, peerreviewed journal of clinical therapeutics and pharmacology focusing on concise rapid reporting of clinical or pre-clinical studies on a range of neuropsychiatric and neurological disorders. This journal is indexed on PubMed Central, the 'PsycINFO' database and CAS, and is the official journal of The International Neuropsychiatric Association (INA). The manuscript management system is completely online and includes a very quick and fair peer-review system, which is all easy to use. Visit http://www.dovepress.com/testimonials.php to read real quotes from published authors.

\footnotetext{
Submit your manuscript here: http://www.dovepress.com/neuropsychiatric-disease-and-treatment-journal
} 